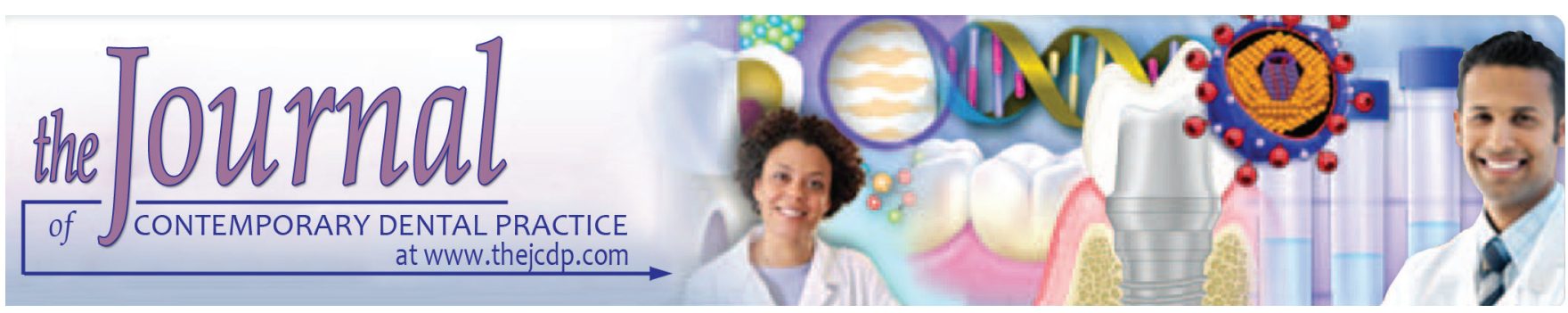

\title{
Ions release Evaluation and Changes in Mini-implant Orthodontic Surface
}

\author{
${ }^{1}$ Marcelo K Suzuki, ${ }^{2}$ Danielle AR Martins, ${ }^{3}$ Marília T Costa, ${ }^{4}$ Andreia C Ferreira, ${ }^{5}$ Flavio AC Ferreira
}

\begin{abstract}
Aim: To evaluate, in vitro, the mini-implant surface changes and the release of ions after immersion in artificial saliva during follow-up of 60 and 120 days.

Materials and methods: As for the surface features, examined in a scanning electron microscope (SEM), before and after immersion in artificial saliva, there was a rough and uneven surface, suggestive of corrosion areas for the two trademarks evaluated after 120 days of immersion. The extracts generated in artificial saliva analysis were submitted to energy dispersive spectroscopy to identify the solid corrosion products produced on the surfaces of miniscrews.
\end{abstract}

Results: Both SIN miniscrews and Neodent brands were observed to release minimal quantities of silver ions, chromium, iron, nickel, titanium, and vanadium. Regarding titanium, this index varied from $88.84 \%$ in the control group of Neodent brand, and $91.29 \%$ in the control group of SIN brand. For the aluminum content, the quantities ranged from $4.91 \%$ in group immersed for 60 days in Neodent brand to $8.71 \%$ for the SIN control group. Considering vanadium, the index ranged from $2.65 \%$ in the group immersed for 120 days to $4.53 \%$ in the control group, both for Neodent brand. Statistically significant differences in iron ion were observed between the control group and the miniscrews brand SIN after 60 and 120 days and for Neodent after 60 days of immersion. The titanium ions suffered statistically significant decrease for both brands after 120 days of storage when compared with the control group.

\footnotetext{
${ }^{1-5}$ Department of Orthodontics

${ }^{1}$ Centro Odontológico Saiki Suzuki, São Paulo, Brazil

${ }^{2}$ Vitae Odontologia, Goiânia, Goiás, Brazil

${ }^{3}$ Instituto Kenedy de pós-graduação, Goiânia, Goiás, Brazil

${ }^{4}$ Instituto Vellini, São Paulo, São Paulo, Brazil

${ }^{5}$ Revista Ortodontia SPO, São Paulo, Brazil
}

Corresponding Author: Marcelo K Suzuki, Centro Odontológico Saiki Suzuki, São Paulo, Brazil, Phone: +551155817241, e-mail: drmarcelo@clinicacoss.com.br
Conclusion: The studied miniscrews showed results consistent with the biosafety of alloys for use, in vivo.

Clinical significance: The knowledge of the physical/chemical state of corrosion products released in the oral cavity is very important for the toxicological assessment of metal alloys used in dental miniscrews.

Keywords: Artificial saliva, Dental implants, Immersion, In vitro techniques, Ions, Laboratory research.

How to cite this article: Suzuki MK, Martins DAR, Costa MT, Ferreira AC, Ferreira FAC. Ions release Evaluation and Changes in Mini-implant Orthodontic Surface. J Contemp Dent Pract 2018;19(8):910-917.

Source of support: Nil

Conflict of interest: None

\section{INTRODUCTION}

Several types of biomaterials are used in orthodontics, which are exposed to the oral environment for a relatively long period, and therefore, suffer a corrosive process. One of the metals used in orthodontics is titanium, with extreme biocompatibility ${ }^{1,2}$ and high corrosion resistance $\mathrm{e}^{2,3}$ present in dental implants (commercially pure) and orthodontic miniscrews (titanium, aluminum, and vanadium alloy), devices used as anchorage in orthodontics., ${ }^{2,4}$

The success of orthodontic treatment depends to a large extent on anchorage devices ${ }^{5}$ and immobility is one of the desired requirements for those devices. ${ }^{6,7}$ Dental implants and orthodontic miniscrews provide stationary or absolute anchorage, important for orthodontic success. ${ }^{8,9}$

The orthodontic miniscrews are used in orthodontics with a high success rate, ${ }^{10}$ with multiple sites of application, quite simple installation, reduction of the risk of surgical trauma and minimum time of osseointegration prior to the application of orthodontic forces. ${ }^{9,11}$ Therefore, stability is directly related to biological factors related to bone quality. ${ }^{9,12}$

Nevertheless, peri-implant inflammation is the main cause of loss of these devices, and the release of metallic 
Ions release Evaluation and Changes in Mini-implant Orthodontic Surface

ions is one of the main causes. ${ }^{13}$ Commercially pure titanium is widely used in the manufacture of dental implants, since it is considered chemically inert, presenting low corrosion and excellent biocompatibility. ${ }^{2,5,14}$ However, the alloys used in the manufacture of miniscrews are not pure, have a higher susceptibility to corrosion and a lower rate of osseointegration. ${ }^{14-17}$

The knowledge of the physical/chemical state of the corrosion products released in the oral cavity is of great importance for the toxicological evaluation of the alloys, as well as for the establishment of criteria for corrosion analysis of the several metallic alloys used in mini dental implants, ${ }^{2,18}$ because they remain in the oral environment for a certain period of time.

Thus, the present study proposes a better understanding of the metallic alloys used in the miniscrews and the observation of alloys' corrosion, verifying possible cytotoxicity to the organism. In this context, the objective of this study was to evaluate, in vitro, the surface alterations of the miniscrews and the products derived from their corrosion, as well as to determine the elements released in the artificial saliva due to the corrosive process.

\section{MATERIALS AND METHODS}

\section{Experimental Design}

Twelve implants of two different brands (SIN and Neodent) were used for in vitro analysis of miniscrew surface changes and determination of the elements released in the artificial saliva by the corrosive process. They were divided into four groups ( $\mathrm{n}=3$ miniscrews in each group): group I: SIN immersed in artificial saliva, group II: Neodent immersed in artificial saliva, group III: artificial saliva (control), and group IV: Implant controls (without immersion).

SIN miniscrews had the following characteristics: Self-drilling, $8 \mathrm{~mm}$ active thread, $1.6 \mathrm{~mm}$ diameter, and $1 \mathrm{~mm}$ transmucosal profile. The Neodent miniscrews had the following characteristics: Self-drilling, $9 \mathrm{~mm}$
Table 1: Composition of artificial saliva

\begin{tabular}{|c|c|}
\hline Artificial saliva & \\
\hline $\mathrm{NaCl}$ & $0.40 \mathrm{mg} / \mathrm{L}$ \\
\hline $\mathrm{KCl}$ & $0.40 \mathrm{mg} / \mathrm{L}$ \\
\hline $\mathrm{CaCl}_{2} \mathrm{H}_{2} \mathrm{O}$ & $0.80 \mathrm{mg} / \mathrm{L}$ \\
\hline $\mathrm{CO}\left(\mathrm{NH}_{2}\right)_{2}$ & $1.0 \mathrm{mg} / \mathrm{L}$ \\
\hline Distilled water & $1,000 \mathrm{~mL}$ \\
\hline
\end{tabular}

active thread, $1.6 \mathrm{~mm}$ diameter, and $1 \mathrm{~mm}$ transmucosal profile (medium strap). All the miniscrews were weighed in analytical balance (Model 410, Kern and Sohn Gmbh, Balingen, German), autoclaved at $120^{\circ} \mathrm{C}$ for 30 minutes, and then divided $(n=3)$ and packed in four glass tubes like vacutainers which are sterile, hermetically sealed, and divided into their respective groups (cited above).

For immersion of the samples, artificial saliva was used as extraction vehicle, $\mathrm{pH}$ 6.76, adjusted and controlled with $10 \mathrm{~N} \mathrm{NaOH}$. The artificial saliva used was a modification of Meyer's solution whose chloride content and corrosive activity were shown to be similar to natural saliva ${ }^{19}$ and whose chemical composition is presented in Table 1.

The amount of artificial saliva used in group III (control) tube was $3 \mathrm{~mL}$, and for groups I (SIN) and II (Neodent), the following ratio was used (according to the International Standards Organization): $0.2 \mathrm{gm}$ of miniscrew for every $1 \mathrm{~mL}$ of saliva. ${ }^{20}$

After the samples were prepared, the hermetically sealed vacutainer tubes were incubated in an oven at $37^{\circ} \mathrm{C}$ and left inert. After each period, the miniscrews were removed from the artificial saliva, washed in deionized water, dried, and stored in hermetically sealed vacutainers. Then, each group of miniscrews (groups I and II) underwent the following procedure: Extracts corresponding to the saliva containing the products of the corrosion of the three miniscrews were mixed in a $15-\mathrm{mL}$ plastic tube and stored in aliquots of $3 \mathrm{~mL}$ at $4^{\circ} \mathrm{C}$ until analysis (Fig. 1).
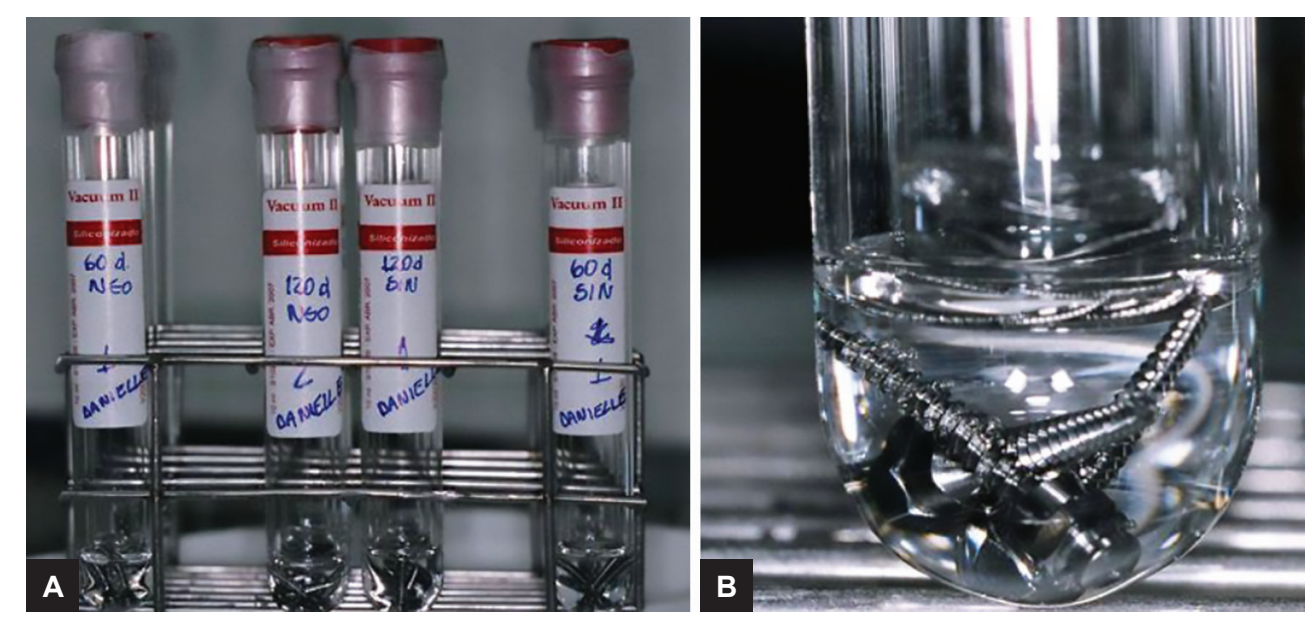

Fig. 1: Preparation of the samples: immersion in artificial saliva 


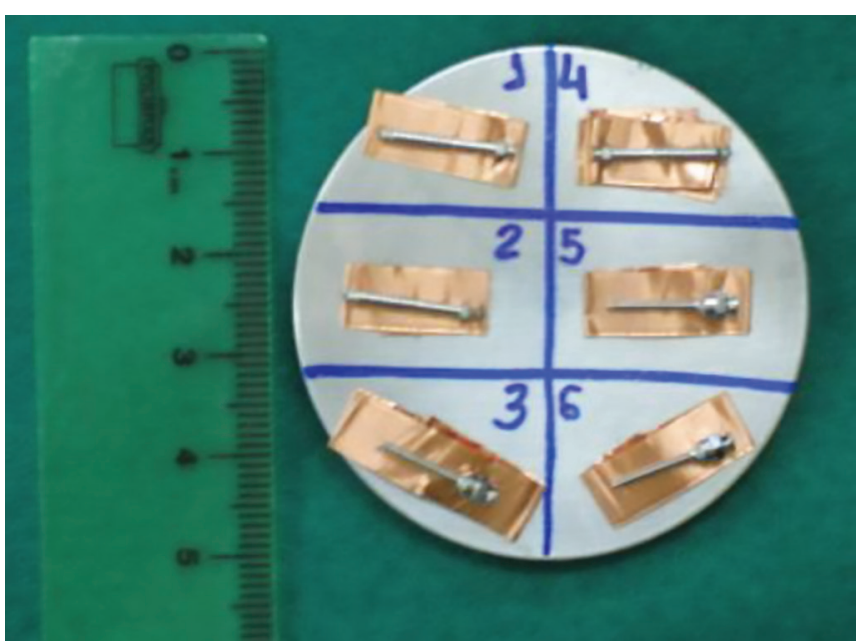

Fig. 2: Preparation of the samples for SEM and EDE

\section{Analysis of the Miniscrews Surfaces under SEM}

In order to evaluate the characteristics of miniscrew surfaces in relation to the presence of imperfections and possible areas of corrosion, a miniscrew from each group was randomly selected and examined by SEM (LEICA, model S440i, 1995). The images were obtained with secondary electron detector, increasing from $200 \times$ to $2000 \times, 20 \mathrm{kV}$, and $0.8 \mu \mathrm{A}^{21}$

\section{Analysis of Corrosion Products by Energy Dispersive Spectrometry}

These same surfaces were analyzed by energy-dispersive spectrometry (EDE) after each immersion period, in order to qualitatively examine the solid corrosion products adhered to the miniscrews' surfaces in a microvolume, equivalent to a $1 \mu \mathrm{m}$ diameter sphere (Fig. 2).

\section{Determination of the Elements released from the Miniscrews in Artificial Saliva by Instrumental Analysis by Activation with Neutrons}

In order to determine the concentrations of the metallic ions released by the miniscrews, the Instrumental
Analysis by Activation with Neutrons method was applied in the solution resulting from the corrosion test $\mathrm{t}^{22}$ with irradiation of $500 \mu \mathrm{L}$ of the dried sample in a polyethylene capsule in the nuclear reactor IEA-R1, together with the element patterns for 16 hours under thermal neutron flux. The analysis of the white (standard) of the artificial saliva before the immersions was also performed. After a certain decay time, the samples and the standard were measured in a hyperpure Ge detector (Canberra) coupled to an integrated signal processor (Model 1510), and multichannel analyzer plate (Canberra System 100). The gamma ray spectra were processed and the radioisotopes formed identified by the half-life; the gamma rays energies and the elements concentrations were calculated by comparative method.

\section{Statistical Analysis}

For comparisons between the two brands, the data were submitted to analysis of variance/Bonferroni statistical analysis $(\mathrm{p} \leq 0.05)$ using the statistical program GraphPad Prism software version 4.00 .

\section{RESULTS}

\section{Analysis of Mini-implant Surfaces using SEM}

In the microscopic images, SIN (control) miniscrews presented a smooth and regular surface, with no adherent particles or spots (Fig. 3). After 60 days of immersion in artificial saliva, they presented a smooth and regular appearance, but with some dark spots (Fig. 4). After 120 days, areas of porosity suggestive of pitting corrosion sites (cavities with depth greater than their diameter) and accumulation of residues on an irregular surface were observed (Fig. 5).

Neodent miniscrews presented a polished and regular surface, with some adhered particles, probably derived from industrial manipulation, and porosity areas (Fig. 6). After 60 days in artificial saliva, they presented few areas of
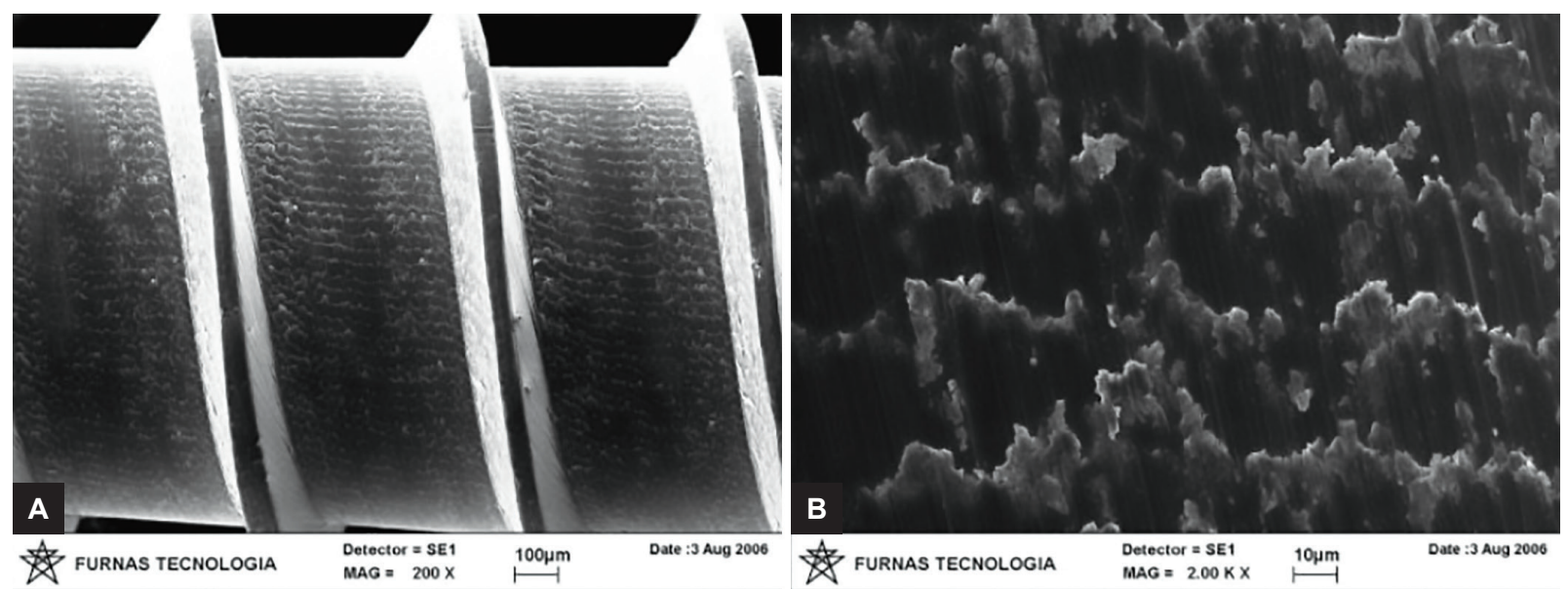

Figs 3 A and B: Miniscrew SIN brand, without immersion in artificial saliva, 200× (A) and 2000× (B) 

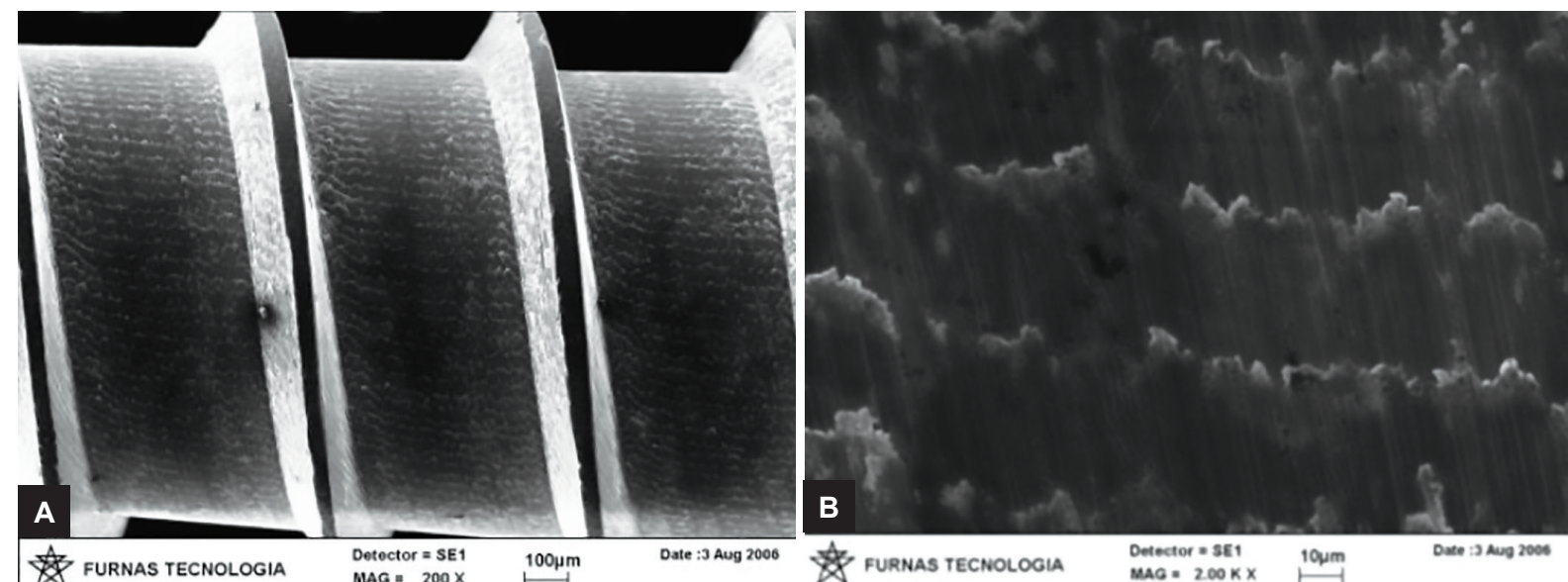

Figs 4A and B: Miniscrew SIN brand, after 60 days, $200 \times(A)$ and $2000 \times(B)$
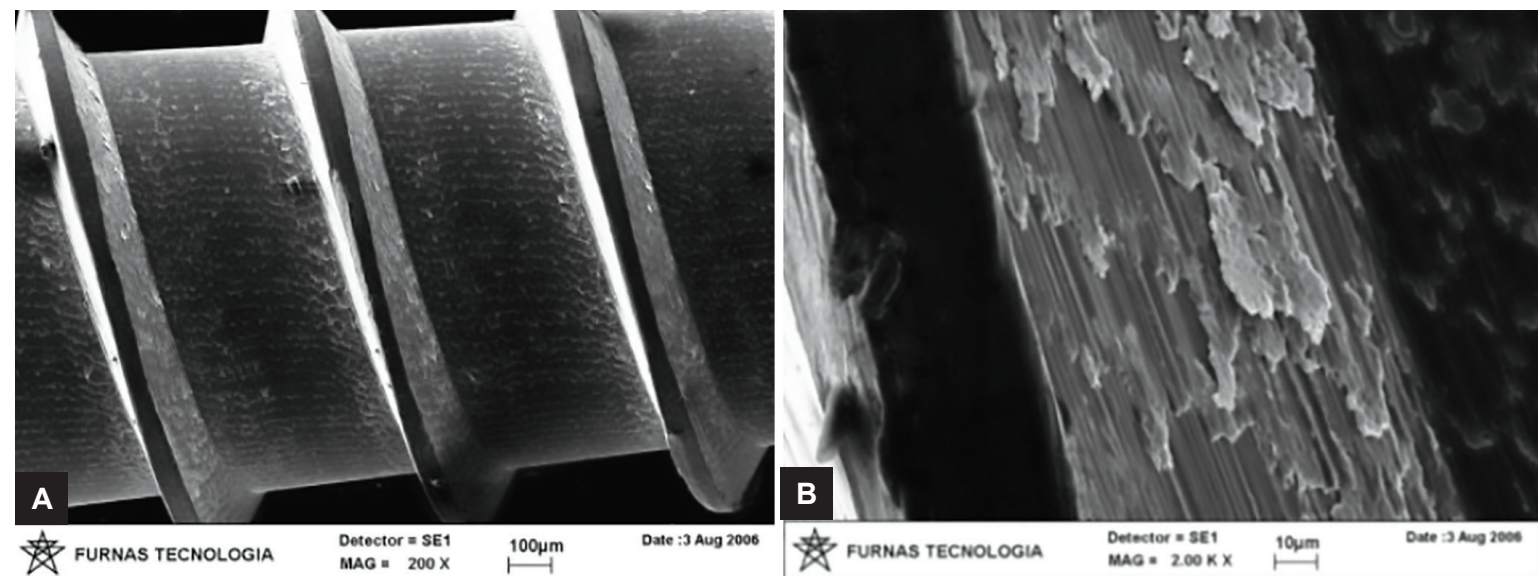

Figs 5A and B: Miniscrew SIN brand, after 120 days, 200× (A) and 2000× (B)
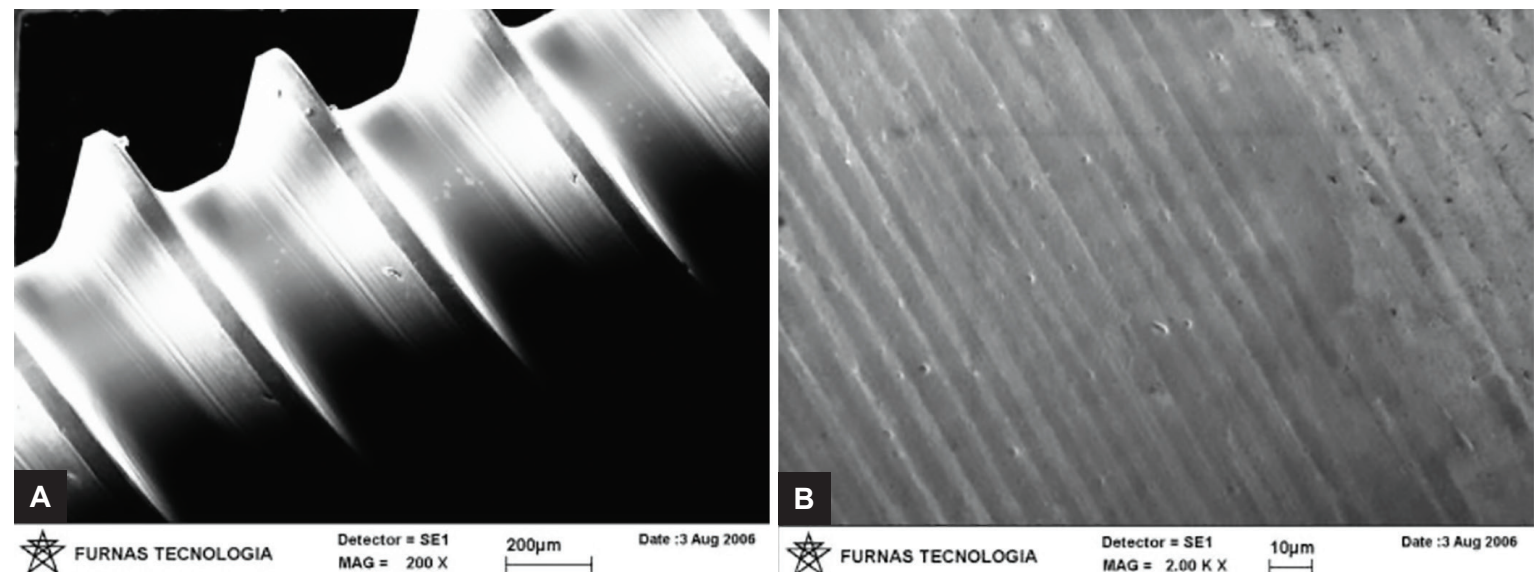

Figs 6A and B: Miniscrew Neodent brand, without immersion in artificial saliva, 200× (left) and 2000× (right)

irregularities and rough surface appearance with several porous sites and some adhered particles (Fig. 7). After 120 days, a rough and irregular surface was observed with porous points, suggesting areas of pitting corrosion (Fig. 8).

\section{Analysis of Corrosion Products by EDE}

This analysis was performed in the dark spots and in the adhered particles of the surface of the two miniscrews brands studied, before and after the immersion in artificial saliva.

According to Table 2, we can verify that in the spectra of SIN control group were verified peaks of titanium and aluminum. After 60 and 120 days of immersion, these values changed and vanadium element was found on the miniscrew surface.

In the Neodent controls (Table 3), peaks of titanium, aluminum, vanadium, and iron were verified. After 60 

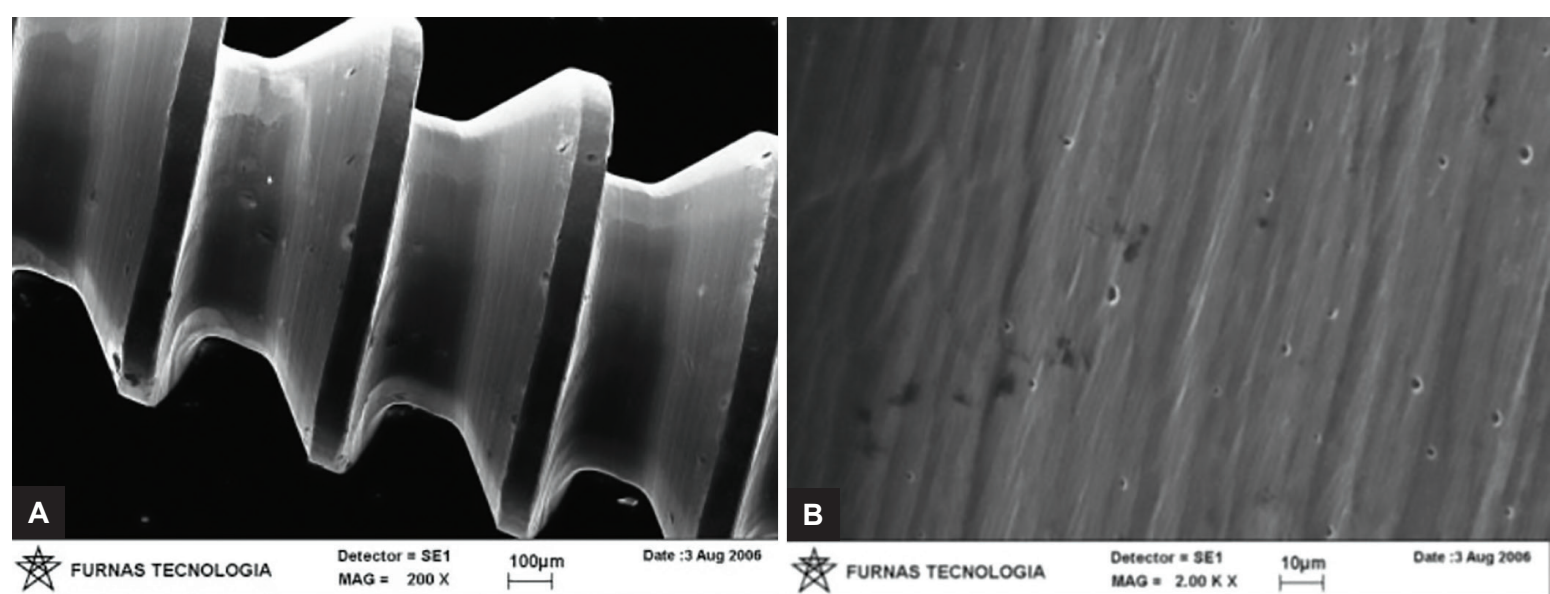

Figs 7A and B: Miniscrew Neodent brand, after 60 days, 200× (A) and 2000× (B)
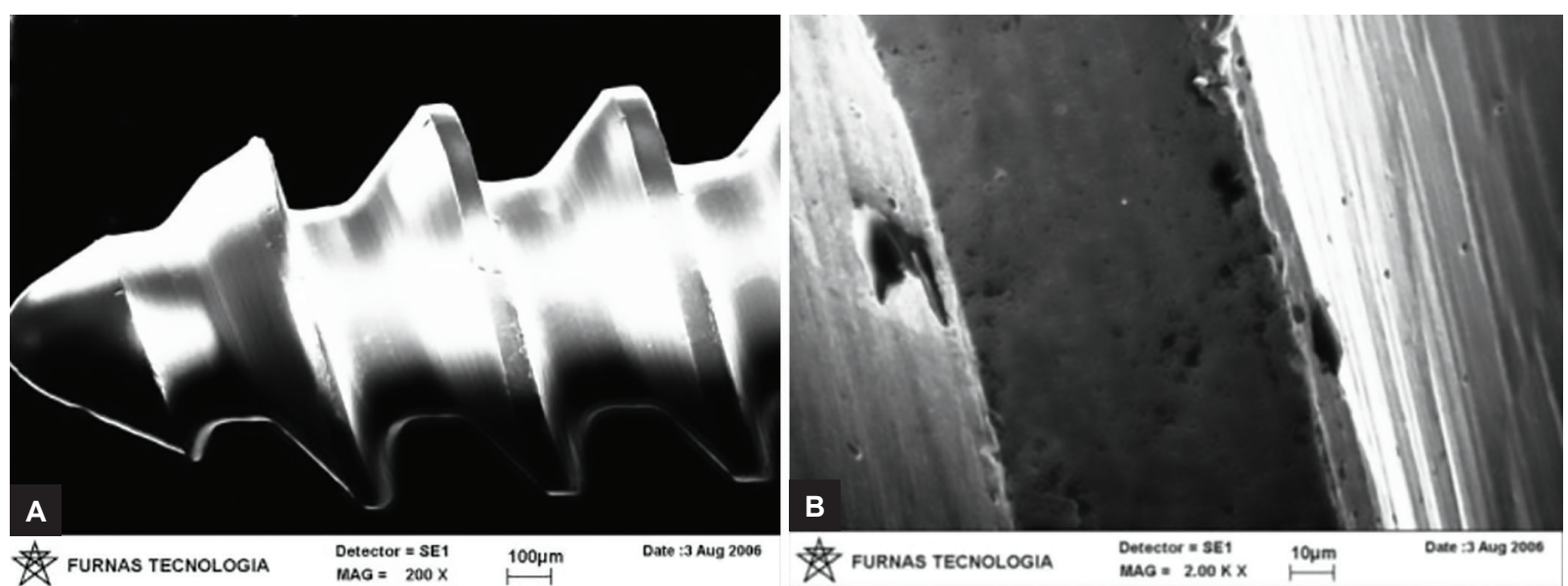

Detector $=$ SE1
MAG $=200 \mathrm{X}$

Figs 8A and B: Miniscrew Neodent brand, after 120 days, 200× (A) and 2000× (B)

Table 2: $\mathrm{Ti}, \mathrm{Al}$, and $\mathrm{V}$ elements of SIN brand during the respective periods

\begin{tabular}{|c|c|c|c|c|c|c|c|c|c|}
\hline & \multicolumn{3}{|c|}{ Titanium } & \multicolumn{3}{|c|}{ Aluminum } & \multicolumn{3}{|c|}{ Vanadium } \\
\hline & Control & 60 days & 120 days & Control & 60 days & 120 days & Control & 60 days & 120 days \\
\hline SIN & $91.29 \%$ & $90.48 \%$ & $89.57 \%$ & $8.71 \%$ & $5.76 \%$ & $6.0 \%$ & - & $3.76 \%$ & $4.43 \%$ \\
\hline
\end{tabular}

Table 3: $\mathrm{Ti}, \mathrm{Al}$, and $\mathrm{V}$ elements of Neodent brand during the respective periods

\begin{tabular}{|c|c|c|c|c|c|c|c|c|c|c|c|c|c|c|c|}
\hline & \multicolumn{3}{|c|}{ Titanium } & \multicolumn{3}{|c|}{ Aluminum } & \multicolumn{3}{|c|}{ Vanadium } & \multicolumn{3}{|c|}{ Iron } & \multicolumn{3}{|c|}{ Sodium } \\
\hline & Control & 60 days & $\begin{array}{l}120 \\
\text { days }\end{array}$ & Control & $\begin{array}{l}60 \\
\text { days }\end{array}$ & $\begin{array}{l}120 \\
\text { days }\end{array}$ & Control & $\begin{array}{l}60 \\
\text { days }\end{array}$ & $\begin{array}{l}120 \\
\text { days }\end{array}$ & Control & $\begin{array}{l}60 \\
\text { days }\end{array}$ & $\begin{array}{l}120 \\
\text { days }\end{array}$ & Control & $\begin{array}{l}60 \\
\text { days }\end{array}$ & $\begin{array}{l}120 \\
\text { days }\end{array}$ \\
\hline Neodent & $88.84 \%$ & $90.77 \%$ & $90.47 \%$ & $5.86 \%$ & $4.91 \%$ & $6.88 \%$ & $4.53 \%$ & $3.6 \%$ & $2.65 \%$ & $0.77 \%$ & - & - & - & $0.72 \%$ & - \\
\hline
\end{tabular}

and 120 days, the values also underwent changes in the peaks of titanium, aluminum, and vanadium (Table 3 ).

According to Table 4, for the Ag and $\mathrm{Cr}$ ions, there was no statistically significant difference between the concentration in the control saliva and the different periods of immersion of both brands.

However, for Fe ion, the difference in their release was statistically significant in all samples, except when compared with the control artificial saliva extract and the Neodent brand extract (after 120 days). There was a statistically significant difference when we compared this ion concentration in the period of 60 days between both brands, with decline of the concentration when we compared the brands separately, from 60 to 120 days.

Considering the Ni ions, there was a statistically significant difference in two situations: In the saliva extracts in the 60-day period for both brands when compared with the control saliva extract, and in the 60-day extract compared with 120 days of the brand SIN.

Considering Ti ions, there was a statistically significant concentration reduction present in the extracts of artificial saliva where the miniscrews of both brands 
Ions release Evaluation and Changes in Mini-implant Orthodontic Surface

Table 4: Ions concentration in the artificial saliva in 60 and 120 days of the two commercial brands

\begin{tabular}{llllll}
\hline & $\begin{array}{l}\text { Saliva control } \\
(\mu \mathrm{g} / \mathrm{mL})\end{array}$ & $\begin{array}{l}\text { SIN } 60 \text { days } \\
(\mu \mathrm{g} / \mathrm{mL})\end{array}$ & $\begin{array}{l}\text { SIN 120 days } \\
(\mu \mathrm{g} / \mathrm{mL})\end{array}$ & $\begin{array}{l}\text { Neodent } 60 \text { days } \\
(\mu \mathrm{g} / \mathrm{mL})\end{array}$ & $\begin{array}{l}\text { Neodent 120 days } \\
(\mu \mathrm{g} / \mathrm{mL})\end{array}$ \\
\hline $\mathrm{Ag}$ & $0.01 \pm 0.006$ & $0.02 \pm 0.008$ & $0.01 \pm 0.006$ & $0.01 \pm 0.006$ & $0.01 \pm 0.006$ \\
$\mathrm{Cr}$ & $0.01 \pm 0.015$ & $0.01 \pm 0.015$ & $0.01 \pm 0.015$ & $0.01 \pm 0.015$ & $0.01 \pm 0.015$ \\
$\mathrm{Fe}$ & $0.71 \pm 0.02$ & $1.24 \pm 0.01$ & $0.82 \pm 0.01$ & $1.08 \pm 0.01$ & $0.72 \pm 0.01$ \\
$\mathrm{Ni}$ & $0.36 \pm 0.01$ & $0.83 \pm 0.01$ & $0.50 \pm 0.1633$ & $0.70 \pm 0.16$ & $0.48 \pm 0.01$ \\
$\mathrm{Ti}$ & $43 \pm 1.63$ & $43 \pm 1.63$ & $32 \pm 1.63$ & $43 \pm 1.63$ & $30 \pm 1.63$ \\
$\mathrm{~V}^{*}$ & $0.005 \pm 0.001$ & $0.01 \pm 0.001$ & $0.002 \pm 0.001$ & $0.006 \pm 0.001$ & $0.003 \pm 0.001$ \\
\hline
\end{tabular}

were immersed for 120 days compared with the control saliva.

Finally, for $\mathrm{V}$ ions, the difference in vanadium release was statistically significant when comparing the concentration in the control saliva extract and the SIN brand saliva extract immersed for 60 days. When comparing the extract of the SIN miniscrews for 60 and 120 days, a statistically significant difference was also observed.

\section{DISCUSSION}

The devices and accessories made from metal alloys of different compositions constitute the professional arsenal tooth movement. ${ }^{15}$ Since the enzymatic and microbiological characteristics of the oral cavity provide a favorable environment for metals corrosion, in recent years, these devices have been widely studied, since this corrosion causes the release of metallic ions that, in toxic concentrations, can lead to adverse physiological effects including cytotoxicity, genotoxicity, carcinogenicity, and allergenic effects. $2,13,23,24$

In order to evaluate the biological safety of new materials, in vitro and in vivo tests have been performed according to the following levels: Level 1 - in vitro (assessing toxic potential, allergenic, or carcinogenic reactions), level 2-in vivo in animals, by implanting the material to be evaluated in appropriate regions so that both function and adverse reactions can be investigated), and level 3involving clinical studies. ${ }^{20,25}$

In the literature clinical studies are reported that aim to evaluate the corrosion of orthodontic appliances in vitro. ${ }^{15,26-28}$ However, the lack of standardization in the experimental design allied to the presence of different electrochemical factors in the studies hinders data reproducibility. ${ }^{18}$ Differences in the experiments design may also occur and the resulting corrosion products may adhere to the metal surface and become unavailable for instrumental analysis of the solutes and may not be observed. $2,13,14,29$

According to Mikulewicz and Chojnacka ${ }^{30}$ and Bortagaray et al, ${ }_{15}^{15}$ the main in vitro tests' disadvantage is that the experiment design does not reflect in vivo conditions, i.e., the presence of biofilm growing on the surface of materials in the oral cavity.
The miniscrews surfaces analysis by SEM showed, in the present study, that the samples did not suffer expressive corrosion, confirming the high corrosion resistance of the miniscrews evaluated. The study conducted by Alves et $\mathrm{al}^{5}$ also showed no evidence of corrosion with the miniscrews made by Neodent ${ }^{\circledR}$ and SIN companies, revealing smooth surfaces.

However, it was observed that the longer the immersion period in artificial saliva, the greater the susceptibility of the surfaces to the appearance of darkened spots. Similar results were observed by Sridhar et $\mathrm{al}^{31}$ through a combination of optical microscopy and scanning electron, who found a positive correlation between corrosion and immersion time.

It was also observed in this study a greater amount of adhered particles and irregularities, favoring the localized attack of corrosion, which can progress rapidly, inducing a greater metal loss of thickness and causing perforations and points of concentration of stresses. This can decrease the mechanical strength of the material by increasing the release of metal ions and the risk of fractures.

An interesting finding in this research was the presence of the sodium ion detected on the surface of the miniscrews by the analysis of EDS, suggesting that this ion may be present in the artificial saliva composition.

In vitro and in vivo studies reported in the literature demonstrate the importance of released metal ions' identification from alloys in the evaluation of toxic effects. ${ }^{2,16,29,30,32-34}$

In the study reported by Marigo et al, ${ }^{13}$ the samples analyzed in the anatomical absorption spectrophotometer showed extremely low amounts of $\mathrm{Ti}, \mathrm{Al}$, and $\mathrm{V}$ in all groups tested. However, significantly higher concentrations of magnesium, aluminum, silicon, phosphorus, sulfur, potassium, calcium, titanium, vanadium, manganese, iron, cobalt, copper, zinc, nickel, and chromium were observed when wires, brackets, and metal bands were stored in artificial saliva. ${ }^{29}$ Silverstein et $\mathrm{a}^{35}$ conclude that ions composition observed by spectrophotometer will depend on the brand of the miniscrew studied.

The results of the present study showed a statistically significant increase in the vanadium release in the artificial saliva extract where the SIN miniscrews were 
immersed for 60 days compared with the artificial saliva control extracts, and in the SIN miniscrews that were immersed for 120 days. According to the World Health Organization (WHO), the absorption of vanadium is approximately $5 \%$, and values above $0.1 \mu \mathrm{g} / \mathrm{mL}$ may indicate excessive exposure. Thus, the amount of vanadium found in the present study does not present risks and toxicity when ingested by the patient.

The amount of titanium ions detected in the artificial saliva extracts analyzed in this study ranged from 32 to $43 \mu \mathrm{g} / \mathrm{mL}$. Titanium is an inert substance with minimal side effects, is nontoxic, and is not retained in the intestinal tract. Therefore, patients who use miniscrews are not at risk of ingesting toxic doses of titanium. ${ }^{2,29,36}$

Chromium is added to the metal alloys in order to form a protective oxide layer, providing an excellent corrosion resistance. The amount of chromium ions released in all samples of artificial saliva extract was $0.01 \mu \mathrm{g} / \mathrm{mL}$. The WHO recommends as acceptable an average daily chromium intake of approximately $33 \mu \mathrm{g}$. Therefore, the amount of chromium found in our study represents no risk of toxicity.

Studies on the corrosive behavior of orthodontic wires, bands, and brackets highlight the importance of the evaluation of the ions release in the oral cavity, emphasizing the evaluation of the nickel release due to the possibility of patient hypersensitivity, leading to allergenic effects. ${ }^{37,38}$ The release of nickel ions found in the present study was $0.83 \mu \mathrm{g} / \mathrm{mL}$ in the artificial saliva extract in which the SIN and Neodent miniscrews were immersed for 60 days.

There is an increase in the ions concentration during the period of 60 days, compared with the concentration in the control saliva, and a decrease in the 120-day period. This fact suggests the possibility of a first ions release in the saliva (60 days), proposing that after this period, ions can migrate from the artificial saliva to the corrosion areas, increasing this area.

Although in vitro corrosion evaluations are important in assessing the biocompatibility of dental materials, the results should be evaluated cautiously, since they only guide some parameters. The present study analyzed a miniscrew randomly, and further studies need to be done to define all of these behaviors described in the study as standard.

In addition, only when compared with in vivo and clinical studies, the biocompatibility of the material can be ensured. In the case of titanium, in vitro, in vivo, and clinical tests show the same results, confirming the high biocompatibility of titanium. ${ }^{2,15,33}$

\section{CONCLUSION}

The results suggest that miniscrews, when analyzed in the SEM, before and after immersion in artificial saliva, showed some dark spots, rough and irregular surfaces, with evidence of corrosion areas after 120 days in artificial saliva immersion.

Through the analysis of EDE, it was verified that SIN brand miniscrews presented titanium, aluminum, vanadium, carbon, and silicon elements. The Neodent miniscrews presented titanium, aluminum, vanadium, iron, sodium, and carbon elements.

After chemical analysis of the artificial saliva, it was observed that the SIN and Neodent miniscrews brands presented silver, chromium, iron, nickel, titanium, and vanadium ions release. However, more tests should be performed, since the study was done in artificial saliva. In vivo tests need to be done to provide a better understanding of the miniscrew corrosion process in the oral cavity, since in vivo tests have the presence of other factors.

\section{CLINICAL SIGNIFICANCE}

The knowledge of the physical/chemical state of the corrosion products released in the oral cavity is of vital importance for the toxicological evaluation of the metal alloys used in miniscrew implants.

\section{REFERENCES}

1. Xavier SP, Carvalho PS, Beloti MM, Rosa AL. Response of rat bone marrow cells to commercially pure titanium submitted to different surface treatments. J Dent 2003 Mar;31(3):173-180.

2. Chandar S, Kotian R, Madhyastha P, Kabekkodu SP, Rao P. In vitro evaluation of cytotoxicity and corrosion behavior of commercially pure titanium and Ti-6Al-4V alloy for dental implants. J Indian Prosthodont Soc 2017 Jan-Mar;17(1):35-40.

3. Cheng Y, Hu J, Zhang C, Wang Z, Hao Y, Gao B. Corrosion behavior of novel Ti-24Nb-4Zr-7.9Sn alloy for dental implant applications in vitro. J Biomed Mater Res B Appl Biomater 2013 Feb;101(2):287-294.

4. Roberts WE, Helm FR, Marshall KJ, Gongloff RK. Rigid endosseous implants for orthodontic and orthopedic anchorage. Angle Orthod 1989 Winter;59(4):247-256.

5. Alves CB, Segurado MN, Dorta MC, Dias FR, Lenza MG, Lenza MA. Evaluation of cytotoxicity and corrosion resistance of orthodontic miniscrews. Dental Press J Orthod 2016 Sep-Oct;21(5):39-46.

6. Faber J, Morum TF, Leal S, Berto PM, Carvalho CK. Miniplacas permitem tratamento eficiente e eficaz da mordida aberta anterior. Rev Dent Press Ortodon Ortop Facial 2008 Sep-Oct;13(5):144-157.

7. Antoszewska-Smith J, Sarul M, Łyczek J, Konopka T, Kawala B. Effectiveness of orthodontic miniscrew implants in anchorage reinforcement during en-masse retraction: a systematic review and meta-analysis. Am J Orthod Dentofacial Orthop 2017 Mar;151(3):440-455.

8. Park HS, Bae SM, Kyung HM, Sung JH. Micro-implant anchorage for treatment of skeletal Class I bialveolar protrusion. J Clin Orthod 2001 Jul;35(7):417-422.

9. Consolaro A. Miniscrews and miniplates generate subabsolute and absolute anchorage. Dental Press J Orthod 2014 May-Jun;19(3):20-23. 
10. Chang C, Liu SS, Roberts WE. Primary failure rate for 1680 extra-alveolar mandibular buccal shelf mini-screws placed in movable mucosa or attached gingiva. Angle Orthod 2015 Nov;85(6):905-910.

11. Consolaro A, Sant'ana E, Francischone CE Jr, Consolaro MF, Barbosa BA. Mini-implantes: pontos consensuais e questionamentos sobre o seu uso clínico. Rev Dent Press Ortodon Ortop Facial 2008 Sep-Oct;13(5):20-27.

12. Kuroda S, Sugawara Y, Deguchi T, Kyung HM, TakanoYamamoto T. Clinical use of miniscrew implants as orthodontic anchorage: success rates and postoperative discomfort. Am J Orthod Dentofacial Orthop 2007 Jan;131(1):9-15.

13. Marigo G, Marigo M, Marigo M. Avaliação "in vitro" da liberação de íons metálicos de mini-implantes ortodônticos (Ti6AI4V) submetidos a processo corrosivo. Orthod Sci Pract 2010;3(9):16-24.

14. Luft S, Keilig L, Jäger A, Bourauel C. In-vitro evaluation of the corrosion behavior of orthodontic brackets. Orthod Craniofac Res 2009 Feb;12(1):43-51.

15. Bortagaray MA, Ibañez CA, Ibañez MC, Ibañez JC. Corrosion analysis of an experimental noble alloy on commercially pure titanium dental implants. Open Dent J 2016 Sep;10: 486-496.

16. Ferguson AB Jr, Laing PG, Hodge ES. The ionization of metal implants in living tissues. J Bone Joint Surg Am 1960 Jan;42-A:77-90.

17. Faria AC, Rodrigues RC, Antunes RP, de Mattos Mda G, Rosa AL, Ribeiro RF. Effect of temperature variation on the cytotoxicity of cast dental alloys and commercially pure titanium. J Appl Oral Sci 2009 Sep-Oct;17(5):421-426.

18. Kuphasuk C, Oshida Y, Andres CJ, Hovijitra ST, Barco MT, Brown DT. Electrochemical corrosion of titanium and titanium based alloys. J Prosthet Dent 2001 Feb;85(2):195-202.

19. Hwang CJ, Shin JS, Cha JY. Metal release from simulated fixed orthodontic appliances. Am J Orthod Dentofacial Orthop 2001 Oct;120(4):383-391.

20. International Standard Organization. Biological evaluation of medical devices - part 5 . Tests for in vitro cytotoxicity. Geneva: ISO; 1999.

21. Gross JM, Nascimento GG, Araújo VC, Bönecker M, Furuse C. Miniscrews for orthodontic anchorage: surface analysis after redrilling and sterilization —an in vitro study. J Contemp Dent Pract 2016 Apr;17(4):300-305.

22. Saiki M, Takata MK, Kramarski S, Borelli A. Instrumental nêutron activation analysis of rib bone samples and of bone reference materials. Biol Trace Elem Res 1999 Feb;71-72: 41-46.

23. Locci P, Lilli C, Marinucci L, Calvitti M, Belcastro S, BellocchioS, Staffolani N, Guerra M, Becchetti E. In vitro cytotoxic effects of orthodontic appliances. J Biomed Mater Res 2000 Sep;53(5):560-567.
24. House K, Sernetz F, Dymock D, Sandy JR, Ireland AJ. Corrosion of orthodontic appliances-should we care? Am J Orthod Dentofacial Orthod 2008 Apr;133(4):584-592.

25. International Standard Organization. Biological evaluation of medical devices-part 5. General biocompatibility testing considerations. Geneva: ISO; 2016.

26. Chaturvedi TP. Corrosion of orthodontic brackets in different spices: in vitro study. Indian J Dent Res 2014 Sep-Oct;25(5):630-634.

27. Souza KS, Jaimes RF, Rogero SO, Nascente PA, Agostinho SM. In vitro cytotoxicity test and surface characterization of $\mathrm{CoCrW}$ alloy in artificial saliva solution for dental applications. Braz Dent J 2016 Mar-Apr;27(2):181-186.

28. Houb-Dine A, Bahije L, Oualalou Y, Benyahia H, Zaoui F. Topographic and chemical surface modifications to metal brackets after a period in the mouth. Int Orthod 2017 Sep;15(3):515-528.

29. Mikulewicz M, Chojnacka K, Woźniak B, Downarowicz P. Release of metal ions from orthodontic appliances: an in vitro study. Biol Trace Elem Res 2012 May;146(2):272-280.

30. Mikulewicz M, Chojnacka K. Release of metal ions from orthodontic appliances by in vitro studies: a systematic literature review. Biol Trace Elem Res 2011 Mar;139(3):241-256.

31. Sridhar S, Wilson TG Jr, Palmer KL, Valderrama P, Mathew MT, Prasad S, Jacobs M, Gindri IM, Rodrigues DC. In vitro investigation of the effect of oral bacteria in the surface oxidation of dental implants. Clin Implant Dent Relat Res 2015 Oct;17(Suppl 2):e562-e575.

32. Mikulewicz M, Chojnacka K, Wołowiec P. Release of metal ions from fixed orthodontic appliance: an in vitro study in continuous flow system. Angle Orthod 2014 Jan;84(1):140-148.

33. Senkutvan RS, JacobS, Charles A, Vadgaonkar V, Jatol-TekadeS, Gangurde P. Evaluation of nickel ion release from various orthodontic arch wires: an in vitro study. J Int Soc Prev Community Dent 2014 Jan-Apr;4(1):12-16.

34. Sheibaninia A. Effect of thermocycling on nickel release from orthodontic arch wires: an in vitro study. Biol Trace Elem Res 2014 Dec;162(1-3):353-359.

35. Silverstein J, Barreto O, França R. Miniscrews for orthodontic anchorage: nanoscale chemical surface analyses. Eur J Orthod 2016 Apr;38(2):146-153.

36. Iijima M, Muguruma T, Kawaguchi M, Yasuda Y, Mizoguchi I. In vivo degradation of orthodontic miniscrew implants: surface analysis of as-received and retrieved specimens. J Mater Sci Mater Med 2015 Feb;26(2):71.

37. Kao CT, Ding SJ, Chen YC, Huang TH. The anticorrosion ability of titanium nitride (TiN) plating on an orthodontic metal bracket and its biocompatibility. J Biomed Mater Res 2002 Oct;63(6):786-792.

38. Kocijan A, Milosev I, Pihlar B. The influence of complexing agent and proteins on the corrosion of stainless steels and their metal components. J Mater Sci Mater Med 2003 Jan;14(1):69-77. 